\title{
Muslims in Germany:
}

\section{In-depth Interviews with College Students on the "Otherness"}

\author{
Dr. Sara S. Elmaghraby
}

Cairo University

Egypt

\section{Abstract}

This paper evaluates the concept of Otherness among the Muslim college students. Primary data was collected in Germany Hamburg and Erfurt during a month. Through in-depth interviews, this paper answers the research questions whether the Muslim College Students in Germany see themselves as the Other or not. It also explores how Muslim College students in Germany perceive their identity, the relation between the Muslim College Students and Society. It also explores the relation between the Muslim College Students and the Media. The findings of this paper show that $\mathbf{9}$ of $\mathbf{1 0}$ students answered that they do not have a German identity and that they are keeping their hometown identity instead. They refuse to give up on their identity and blend in German society. The only exception to this was a Muslim German convert who is originally German. This shows that most of the student has a feeling of being the other in German society and can never feel fully integrated into German society. It also discovered that most of the college students did not participate in any of these activities but would prefer to participate in Muslim activities on a political or societal level. Furthermore, this paper discovered that 6 of 10 of the interviewed students were only using social media that is mainly concerned with their ethnic or religious community. Because of the language barrier and the lack of time and willingness, only 2 students followed German TV channels and or newspapers and magazines. 


\section{Introduction}

"Otherness" is a term that is influenced by Hegel and Freud "the other" that became a central theme in the French philosophy in the 20th century. According to French philosophy, three definitions were given to the term "the other". The other could be defined as another individual, another mind and body that is largely "unknowable to the interpreting self", or construction in opposition to the self, or something more than someone outside or opposed to the self.

According to De Beauvoir (1949), the term of the "Other" is as fundamental as consciousness itself. Otherness is a fundamental category of human thought because there is no group ever that has defined itself without simultaneously posting the Other facing it. He introduced the notion of "the other" as opposing to "the Self". Until then the concepts of "otherness "Othering" and "the other" are concepts that moved to all sciences ending to media studies. De Beauvoir's ideas were rooted in Hegel 's "Master-Slave dialectic" in which the relation between the political historical dimension is opposite with the more fundamental, psychological dimension (De Beauvoir, 1949).

Researchers differentiated between three terms the Other who is a member of a dominated out-group, whose identity is considered lacking and who may be subject to discrimination by the in-group, Othering which is transforming a difference into otherness to create an in-group and an out-group and the Otherness which are the characteristics of the Other (Lennette, 2017).

Othering is the simultaneous construction of the self or in-group and the other or out-group in mutual and unequal opposition through the identification of some 
undesirable characteristics that the self-in group has and the self/in-group lacks. Othering thus sets up a superior self/in-group in contrast to an inferior other/ out-group, but this superiority/inferiority is nearly always left implicit. This is rather "crude othering". (the undesirable characteristics) There is rather a more "sophisticated" kind of othering. The "crude" othering is rather about the distribution of undesirable characteristics that are assumed or posited. The "sophisticated" on the other side is a result of an argument that is partially based on a self-other-identifying assumption. (the relatively neutral differences "Both are about a perceived difference between the self/in-group and the other/ outgroup. Thus, there is no clear boundary between the crude and the sophisticated othering: the first can turn to the second and the second when looked at closely could have lost its original argument and became the first (Brons, 2015). According to the cultural geographer Crang (1998), othering is "a process.... through which identities are set in an unequal relationship."

In the feminist and post-colonial ideas, othering is explained as the politically charged self-identification using destination from the other. Othering according to Hegel is psychological and political. When there is an accusation of othering, we mean an accusation of political incorrectness in-correctness or a "thought crime". Gutman (2018) Frantz Fanon developed the idea of the other in his writing to be a key concern in postcolonial studies. To him, the other is not me: he is the other. The other is someone who -by definition- lacks identity, propriety, purity, and literality. He can be described as the foreign or the one who does not belong to a group, who does not speak a given language, who does not 
have the same customs. The other is the" unfamiliar, uncanny, unauthorized, inappropriate and the improper" (Al- Saidi, 2014).

Cahonne (2003) defines the postmodern "other" as:

"The apparent identity of what appears to be cultural ... like humans. Words, meanings, ideas, etc. are maintained only through repression, an active process of exclusion, opposition, and hierarchization."

The concept of the Self and the Other is used which is an important idea that helps us understand how meanings are being shaped, created or reinforced in a text. The triangulation of otherness the mediator, the observer, the subject, the self, and the object the other (Cahonne, 2003).

In his highly important 1983 book "Imagined Communities: Reflections on the Origin and Spread of Nationalism", Benedict Anderson talked about the nation as an "imagined political community". He explained why communities are imagined. Members of even the smallest nation will never know most of their fellow members, $(\ldots .)^{\prime \prime}$ so groups always develop a sense of commonality about each other (Anderson, 1983).

\section{Otherness and discrimination}

Otherness is not only about the difference between me and the Other but also the point of view and the discourse of the person who perceives the Other. Opposing Me, us (the Self), and You, them (the Other) humanity is divided into two groups: one group that has the norm and whose identity is valued. The other group is defined according to its faults, devalued and prone to discrimination.

Only dominant groups (such as western society) can impose their categories. By describing them as Others, 
The Barbarians, The Savages or The People of Color, they relegate the peoples that they could "dominate or exterminate to the margin of humanity". The otherness of these peoples has notably been based on the process of marginalizing these groups in space and psychology. The marginalization in space, like segregation or territorial constructions, would help accentuate and maintain the differences between the Self and the Other. Sometimes the Other would pretend that the Other is valued and exotic to give himself a feeling of comfort and deny his feeling of superiority.

The ethnocentric bias that creates otherness is doubtlessly an anthropological constant. All groups tend to value themselves and distinguish themselves from Others whom they devalue. But the forms of this ethnocentrism are varied and have been constructed by discourse and practice through history. Certain constructs are specific to certain societies and others seem universal (malefemale) western society stands out for two reasons than all other societies.

First otherness and identity are based on binary logic. Western thought has been since the time of Aristotle attached to its identity and the law of noncontradiction. They have excluded the middle class and produced several binaries that oppose a positively connoted term and a negatively connoted term and thus lends itself well to the construction of the self and the other. Dichotomies exist male versus female, white versus black, believer versus non-believer.

Second, the era of the colonization helped the West exporting its values. These values would be acknowledged everywhere and enforced in cultural integration processes. Western categories of identity and otherness, 
transmitted by the West, have become available far beyond the boundaries of the West (Staszak, 2008).

Edward Said has linked in his 1978 book Orientalism the "Other" with exoticism, the commercial exploitation of constructed otherness to analyze the Occidental picture of the Orient." The author's ethnographic report is a reversed mirror image of his ethnocultural ideal (Said, 1978).

According to Brons (2015), two examples of othering are the "Amoral Atheist" and the "Irrational Women/ East". The Amoral Atheists can have hidden arguments of firstly that moral beliefs are religious beliefs and that the other has no religious belief and therefore he would have no moral beliefs. The underlying argument of the Irrational Women/East lies from the orientalist and sexist myths of the rational and superior West/the Male versus the emotional less rational inferior East/ the women. Othering is a self-other distant ting and dehumanizing the other process. The other could have dimensions one the inferior versus the radically alien. There is othering that could be the individual "Me versus you" othering and another then social Us versus Them.

When defining discrimination, two questions should be asked. The first question is to whom discrimination is there done (to which gender, religion or ethnicity). This could also be described as a categorical discrimination /group related discrimination. The second question is the actions towards those people. Is the discrimination structural, formal, work or legal level or is the discrimination a micro-discrimination? Micro discrimination means everyday discrimination, verbal, visual or feeling or look discrimination.

All the previous studies showed how worthy it is 
to study the effect of the media on the majority and minority, and to analyze the perception of discrimination among the minority, whether this discrimination in the "real" discrimination that is put by law and society and the rather "perceived" discrimination that the minority feels and perceives.

\section{Otherness and the Media}

In his book, Van Dijk (2000) talked about the role of the media in general and news in the reproduction of racial and ethnic inequality in societies. He talked the term New(s) Racism to describe a difference from old racism of slavery where minorities are with cultures and where racism is related to a rather "symbolic" and "everyday racism." The new forms of racism are discursive, expressed, enacted and confirmed by text and talk. According to Van Dijk, racism is a social system of ethnic and racial inequality that has a discursive reproduction. The racist discourse has two dimensions the social and the cognitive. The social dimension could be either a micro-level as in everyday discrimination and on a macro level such as organizational and structural structure. The cognitive dimension of racist discourse lies in the beliefs of the people.

The power is practiced over the most influential form of public discourse: the media discourse. The media discourse is combined with a lack of alternative sources that are like a consensus. Opponents and dissident groups (the Other) are weak. In this case, the media can abuse such power and establishes a discursive and cognitive hegemony that is needed for the reproduction of the new racism.

He explains that the power in the news is seen in six 
categories. The first category is news making. Minorities have less access to the media and therefore fewer sources; their opinion is heard less and therefore less credible and less newsworthy. The second category is the news structure which means the structures and the strategies of news discourse that come from the authority and the White elite. The third is the topics that mainly focus on threats and violence, on illegal immigration and social problems and cultural characterization. Fourth are the quotes where the minority representatives are seldom allowed to speak alone. The fifth is local meanings which are the meanings of words and sentences, the use of special codes, words and lexical choice of words. The last is the form, the formulation, and the expression. In other words, the underlying beliefs of speakers, the big headlines and the passive-active sentences (Van Dijk, 2000).

This study seeks to answer some research questions that are related to the Otherness, the Othering and the discrimination in the German Society towards Muslims in general and Muslim college students in particular.

\section{Research Questions:}

The research core question is whether the Muslim College Students in Germany see themselves as the Other or not. The sub-research questions are as following:

RQ1: What is the Identity of the Muslim College Students in Germany?

RQ2: What is the relation between the Muslim College Students in Germany and the Society?

RQ3: What is the relation between the Muslim College Students in Germany and the Media? 


\section{Methodology}

In this research, I wish to obtain more detailed and thorough information on the Otherness among college students. Therefore, I have decided to use an in-depth interview as a tool for collecting data. Gabler (2013) defines an in-depth interview as a form of a non-standard or semi-structured oral interview with a relatively large freedom of the interviewer in terms of content and design, which increases willingness to provide information and the spontaneity of the respondents should be higher.

I have followed a schedule of pre-prepared questions but was also able to deviate where necessary to maximize the information obtained. The structured interview was taken by me but not rigidly followed. The interview structure was kept flexible. Applying a specific guide to maintain a degree of control, I allowed the interviewee to choose pseudonyms and reiterated the voluntary nature of their participation. I understand the limitations of the in-depth interviews and that in-depth interviews are prone to bias, were very much time-intensive, and that the results are not generalizable.

The steps of the in-depth interview were taken, interviews were planned, college students who were involved in the research were identified, the information needed to be identified, the international and national ethical research standards were revised. Interviews were taken.

Participants (college students) were put at their ease with general introductions and permissions (consent) for interviewing and recording the interviews. Details on confidentiality were given about the anonymity of the information and sensitivity concerning its later usage, a brief background about the study was given 
to help contextualize the focus of the questions and responses. After the introduction four main stages were held: Background, letting off the steam, addressing the issues and lastly typing and debriefing. The data of the interviews were collected analyzed and written in a final report (Boyce \& Neale, 2006).

In-depth interviews were conducted with Muslim students around different cities in Germany (at the Free University of Berlin, the University of Hamburg and the University of Erfurt)

Using snowballing as a process in which contact is made with participants was appropriate for the research. Through whatever access route one can find and through these first participants, I was introduced to another of similar, relevant characteristics for the research. This was an integral part of ethnography which involves spending time in the field with the group under study and has helped in contacting hard to reach groups and individuals. I have used in each university a facilitator a friend or a colleague to introduce me to the interviewees and make them feel at ease when talking to me. Interviewees were asked if they allow audio-recording and written notes were taken by me.

One of the challenges I have faced was the unwillingness of some of the Muslim college students to be interviewed because they felt as members of marginalized groups. I have chosen the university campus (the cafeteria, the garden, the library or in front of the mosque) to conduct the interviews.

Interviews were conducted in English, some in German, others in Arabic according to the preferences of the participants. Being able to speak all the three languages fluently has enabled me to make the participants feel at 
ease while taking in the mother tongue. Some interviews were interlanguages. Because I am Muslim myself and wear a Hijab, I felt an interviewee and interviewer match that made participants feel at ease especially when talking about sensitive issues.

The in-depth interview was designed in three categories as follows: (The detailed questions are in Appendix)

Category One: Identity: A-Demographics, Age, City, Gender, Hijab, Beard, Education, Muslim: (Sunni, Shiite, Secular), Ethnicity: Egyptian, Pakistani, German, Place of birth: Inside Germany, Outside Germany, Generation in Germany, Mother Language, German language proficiency: Excellent- Good- Limited-None, Type of college study: Human, Science, Math.

Category Two: Relation with Society: A-Integration, Discrimination, Prejudices B-Political and Community Engagement in Muslim organizations and/or mosques and non-Muslim mainstream activities.

Category Three: Media: A-Mainstream Media B-Minority Media (Diverse, Migrant media).

After conducting the in-depth interviews, I have conducted a thematic analysis. I have transcribed all interviews and went on all the steps of thematic analysis suggested by Braun and Clarke, 2006. Thematic analysis is the best tool when faced by several qualitative data from interviews or focus groups. This analysis shows the similarities and differences in qualitative data. All the transcripts were printed out, read carefully and first impressions were collected. I have highlighted important sentences and quotes and labeled important words and sentences. Similar ideas were collected and coded into initial codes. These codes created initial themes. The 
initial themes were subtracted from the final themes.

\section{Findings:}

In the findings, I am going to present the data collected from the in-depth interviews. I will start by describing my sample and their demographics. Then I am going to conduct a step by step thematic analysis in which I am going to apply all steps needed for thematic analysis. The last part of the findings will include the interview responses.

Table 1 presents a clear conception of the participants involved in the in-depth interviews.

\section{Table 1: Participants`demographics in focus} groups.

\begin{tabular}{|l|l|l|l|l|}
\hline Participant & Age & Gender & Nation & $\begin{array}{c}\text { City of } \\
\text { Residence }\end{array}$ \\
\hline P1 Moez & 27 & M & Yemen & Erfurt \\
\hline P2 Anonymous & 27 & M & Morocco & Erfurt \\
\hline P3 Abdallah & 30 & M & Syria & Erfurt \\
\hline P4 Anonymous & 20 & F & Turkey & Hamburg \\
\hline P5 Anonymous & 27 & F & Turkey & Hamburg \\
\hline P6 Lilli & 21 & F & Germany & Erfurt \\
\hline P7 Adham & 19 & M & Syria & Erfurt \\
\hline P8 Ahmed & 25 & M & Egypt & Erfurt \\
\hline P9 Yosra & 39 & F & Egypt & Erfurt \\
\hline P10 Anonymous & 21 & M & Turkey & Hamburg \\
\hline S0urce: Author. & & & &
\end{tabular}

Source: Author.

\section{Familiarizing with the data and generating initial codes:}

I am trying in this part after transcribing the interviews and reading the data repeatedly to familiarize myself with data. Then I am producing the initial codes and creating 
meanings as depicted in Table 2.

Table 2: Initial Codes from the transcripts.

\begin{tabular}{|c|c|}
\hline Initial codes & Citations \\
\hline Non-German identity & $\begin{array}{l}\text { "There is no doubt that my identity is } \\
\text { Arabic, and I mainly belong to my country." } \\
\text { (P1) }\end{array}$ \\
\hline German identity & $\begin{array}{l}\text { "I am German and I belong fully to } \\
\text { Germany" (P6) }\end{array}$ \\
\hline $\begin{array}{l}\text { Connected to German } \\
\text { society }\end{array}$ & $\begin{array}{l}\text { "I am connected to the German society: no } \\
\text { doubt" (P6) }\end{array}$ \\
\hline $\begin{array}{l}\text { Not connected to } \\
\text { German } \quad \text { society }\end{array}$ & $\begin{array}{l}\text { "Meine Kultur bleibt (my culture stays)" } \\
\text { (P4) }\end{array}$ \\
\hline $\begin{array}{l}\text { Exposed to } \\
\text { discrimination }\end{array}$ & $\begin{array}{l}\text { "People would look to me, they would stare } \\
\text { very weirdly at me and sometimes I would } \\
\text { be Migrantin (immigrant)." (P4) }\end{array}$ \\
\hline \multirow[t]{2}{*}{$\begin{array}{l}\text { Not exposed to } \\
\text { discrimination }\end{array}$} & $\begin{array}{l}\text { "I sometimes hear curses from people in the } \\
\text { street, people would call for killing Muslims } \\
\text { and migrants. (P5) }\end{array}$ \\
\hline & $\begin{array}{l}\text { Laws are clear and everyone knows his } \\
\text { rights and his duties. Especially at the } \\
\text { university and in academia. (P1) }\end{array}$ \\
\hline $\begin{array}{l}\text { The audience of } \\
\text { German media }\end{array}$ & "I watch all the media" (P6) \\
\hline $\begin{array}{l}\text { The audience of Non- } \\
\text { German media }\end{array}$ & $\begin{array}{l}\text { People are the main source of information, } \\
\text { not the media". (P7) }\end{array}$ \\
\hline
\end{tabular}

(Source: Author)

\section{Initial Themes and Final Themes:}

After coming up with the codes and according to the thematic analysis, one must identify initial themes then 
sum them up into the final themes of the study. I have created 8 initial themes: German versus Non-German identity, connected versus disconnected to German Society, exposed versus non exposed to discrimination and watching versus not watching German media. I have then decided to sum these initial themes into one final theme that includes four subthemes as shown in Figure.

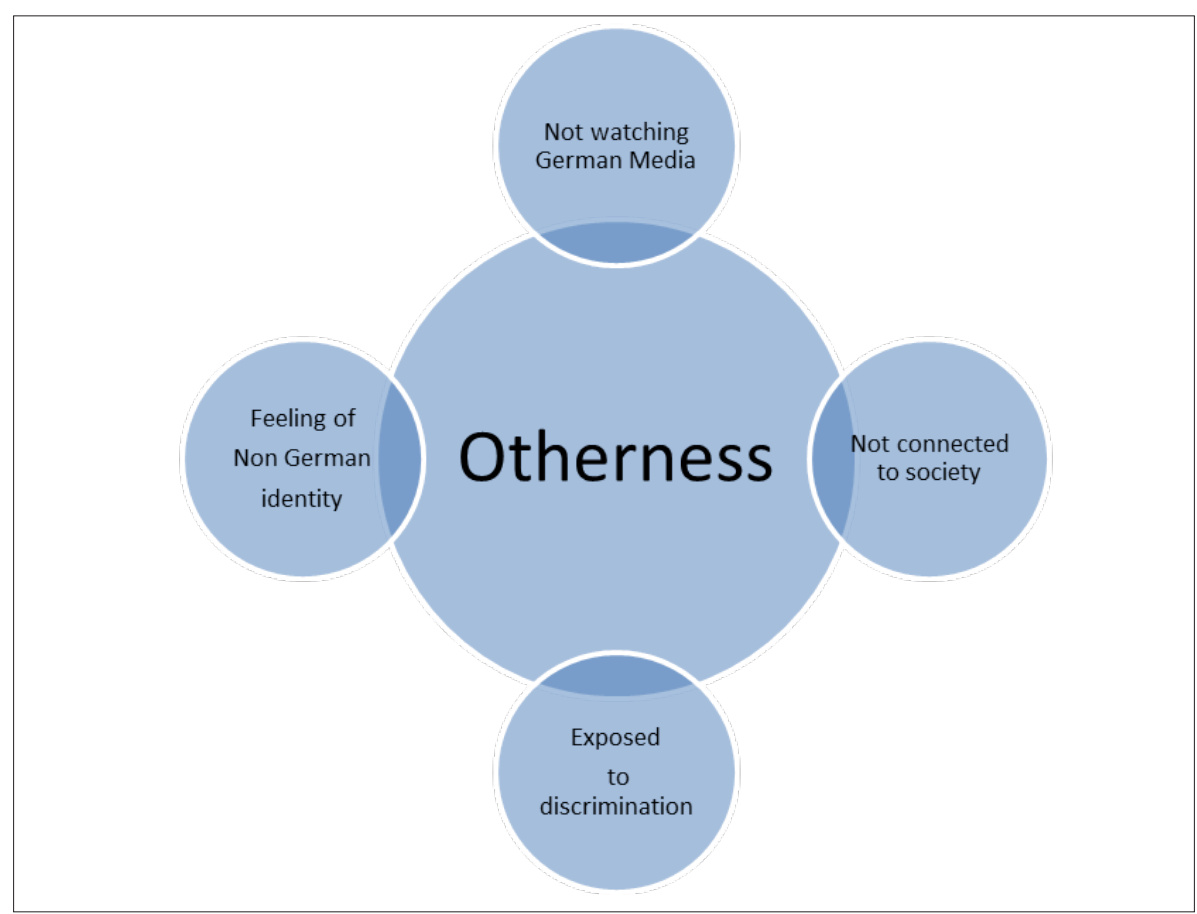

Figure 1. Main Themes (Source: Author)

\section{Interview responses:}

After describing the one theme that this study is about and that is concluded from the transcripts, I explain in this part the responses of the interviews and choose some of the quotations to answering the research question. 


\section{RQ1: What is the Identity of the Muslim College Students in Germany?}

This research question tries to seek answers related to the demographic information of Muslim college students such as age, gender, ethnicity, mother tongue and the place of birth. Other questions were asked related to their religion such as whether they are wearing the hijab (women), have a beard (men), are Sunni, Shiite or secular. Participants were also asked about what they study and when they moved to Germany. Then participants were asked to describe whether they consider themselves part of German society and to describe their national identity and most important belonging.

Moaz Abd Elwahady, 27 years, comes from Yemen and studies MA in psychology. He is a Sunni Muslim. He explains: "My family came from Sunni areas in Yemen that is why I am Sunni. It honestly doesn't matter to me." His mother tongue is Arabic, and his German is very good. He came to Germany to pursue his Masters. (P1) When asking him about whether he is fully integrated or not he answered: "It depends on the meaning of integration. What I know is that I accept many things in this society and this civilization. There is no doubt that my identity is Arabic, and I mainly belong to my country." (P1)

A student who is 27 years old and comes from Morocco explains to me that he came to Germany four years ago to study construction and has studied German to level DSH 2. "I don't consider myself part of the German society. I am an Arab from Arabic origin and I will never be German. The way these people live is the most that makes me feel not belonging. Everything: the traditions, the norms, the language is keeping me away from being 
fully integrated. Although I not fully integrated, I can tell you that I have never - on a personal level- witnessed any type of discrimination... nothing at all... Thank, God." (P2)

Abdullah, 30 years, arrived in Germany from Syria three years ago to pursue his studies in medicine. "I don't consider myself part of the Germany society, I can't adapt till now, I still don't know customs and traditions. I am even still learning the German language and I don't know much about Germany culture", he explains. (P3)

\section{RQ2: What is the relation between the Muslim} College Students in Germany and the Society?

In this question, I investigated the feeling of integration, discrimination, and prejudices among Muslim college students. The interviewee was asked whether they feel integrated into the German Society if they have suffered from discrimination whether in their everyday or their formal level.

A female Hijabi who is 20 years old, born in Germany tells her story: "I live in Hamburg, I am Sunni and I am of Turkish origin. I speak Arabic, English, and German. Both Turkish and German are my mother tongue." When asking her about how integrated she is, she answers that she is integrated but that she does not feel assimilated because she is trying to keep her culture. "Meine Kultur bleibt (my culture stays)" she says. Although she describes herself as German Turkish, she declares that she sometimes faces discrimination. "People would look to me, they would stare very weirdly at me and sometimes I would be Migrantin (immigrant). (P4)

Another female Hijabi student who lives in Hamburg and is of Turkish origin agrees that she has faced lots of 
discrimination in her everyday life. "I sometimes hear curses from people in the street, people would call for killing Muslims and migrants, some would show me their middle finger or stare at my Abaya very weirdly. In severe cases, you could be physically attacked among youth who are drunk in the streets. I honestly feel I am European torn between two sides". (P5)

Abdullah from Syria has also lots of times been exposed to discrimination. People would ask him what he is doing in their country and would ask him to leave Germany and fly to Saudi Arabia. He was even kicked out of an apartment a couple of times. (P2)

Lilli Trebs, 21, studies in Erfurt explains: "Although I am German, I am excluded because of my hijab from many professions. I cannot work as a judge, as a lawyer or as a teacher." (P6)

"Some Germans have wrong thoughts and ideas about Arabs and Muslims; from my side, I try to correct them." (P7) "The image of Muslims and Islam is unfortunately associated with the refugee, the crimes and the poverty. Germans would evaluate us according to our looks and would use prejudgments and stereotypes when dealing with us". (P8)

"The fault is not the Germans. It is mine. I prefer not to integrate, and language is my main barrier. Once I was at a clinic and an old lady refused to answer me in English when she realized that I don't know how to speak German. I decided I will never wear a Hijab in Germany. I used to be active socially and politically in my hometown. When I came to Germany I stopped. The language is my barrier. (P9)

"There is no discrimination in Germany. Laws are clear and everyone knows his rights and his duties. Especially 
at the university and in academia. The university is also multi-cultural and people are used to dealing with different cultures and religions. In the streets, sometimes you could face discrimination according to the place you go to and the people you deal with". Moaz explains that when he first came to Germany, he would be stopped frequently from the police to be checked and that was causing him a lot of pain. People would look "weirdly" to his mum because of her Hijab. (P1)

In this research, I also investigated the political and community engagement, by asking the participants whether they try to be part of Muslim organizations and/ or mosques to feel integrated and whether they try to integrate themselves in political and societal non-Muslim mainstream activities.

Students who participate are active in university groups or mosques. Lilli is a member of a university group for Islamic dialogue that is related to humanitarian projects and social activities. (P6) An anonymous girl from Hamburg explains that she is taking part in Muslim organizations and mosques such as the Islamic Highschool Society (Islamische Hochschule Gemeinde) and that she helps Syrian asylums in their study and their life. (P4) Moaz explains: "My only connection to the Muslim community is when I visit the mosque every Friday or on Muslim feast days. (P1)

Most of the students are not active in political or social life in Germany. "I'm not participating in activities concerning Muslims, but I have once attended a seminar in Berlin about religions. And it was an interesting discussion. I would never participate in any group or Facebook page that is related to Muslims or Syrians." (P2)

Students who do not participate in Non-Muslim 
organizations explain that: "I don't participate in activities related to Germany political parties etc...and not online (Anonymous, 27, Erfurt). Some of them decide not willing to participate at all and others explaining that they are planning to be more active in the future: "Till now, I'm not involved in activities about Germany, but I want to be more participated".(P7)

.. as a Muslim, I do the normal Muslim rituals like the praying, the Friday prayers, I am not active on the internet (Anonymous, 27, Erfurt)

no, I am not a part of Muslim organization or mosques, I consider myself as a non-active Muslim, (P5)

\section{RQ3: What is the relation between the Muslim} College Students in Germany and the Media?

The interviewees were asked to describe their relationship to the Mainstream and the Minority Media. They were asked to determine their usage to mainstream media and SNS, to describe if the media presents the various religious groups and Muslims positively or negatively and to evaluate the role of the mainstream media in the portrayal of Islam.

"I watch all the media", says (P6). "I have a Facebook account. And I follow German and Muslim media." "The most relevant Muslim media that I follow is Qantara a website for enhancing dialogue with Muslims, Mada Masr and the Syrian-German Forum for Dialogue. From the German media, I watch Tagesschau, read some magazines like der Spiegel and rarely watch TV."

It is common among the participants that they do not prefer watching the Television or listen to the radio. "I don't like watching T.V, but if I do, then it is some German programs especially talk shows. (P1)

Concerning the Minority media or the so-called diverse 
or migrant media, participants were asked to describe their relationship to the minority media, the reasons behind them using this media or not and determine the role of this media in the portrayal of Islam.

Facebook is one of the main sources of information for most of the interviewees. "I'm a very active member on Facebook. I use Facebook to follow political issues related to Yemen. I am using Facebook to support the past president of Yemen. But I rarely discuss any topics related to religion". (P7)

I watch Yemeni and Egyptian programs on T.V all the time. When I watch German television, I am mainly intending to improve my language skills." (P7) He continues: "People are the main source of information, not the media".

The most relevant German media read by participants are Der Spiegel online, Bild and Die Zeit. On TV, it is mainly RTL and late comedy shows. The most relevant media outlets Turkish students watch are CNN Turk, Artv, TRT 1.

"I generally don't watch Tv. Social media are my main source of information. I read Deutsche Welle in Arabic and English, read CNN, The Washington Post. Etc. I also have a Twitter account. That is the only media I consume. I don't trust the home media (P9) On the contrary, some participants are still connected closely to their home country media. "I watch only in Egyptian movies. I also have accounts on Facebook and Instagram." (P2)

When asking the participants whether the media depicts Muslims and Islam fairly and honestly, all participants who follow the media agree on a distorted image towards Muslims and Islam. "There is for sure racism and discrimination in the image of Muslims in 
the German media. When a Muslim commits a crime, the media would only focus on his nationality and his religion. If the criminal is a non-Muslim, the media coverage changes. I just cannot help myself blaming the Muslims themselves for doing nothing to improve their image". (P2) An anonymous female student in Hamburg agrees. "The media influences the image of Islam very negatively. I always react and try to answer everyone and defend all the claims as much as I can. (Anonymous 27 Hamburg) But most of the time this is not the case. "Muslims are too passive to answer or defend Islam. They rarely do any blogs, any events or comments on the news", another anonymous student answers. (P4)

"I have never watched anything related to the image of Islam in any of the German media that I follow, says an anonymous student, "there is nothing about Islam neither positive nor negative" (P2)

\section{Conclusion:}

This paper was seeking to answer three research questions as follows:

RQ1: What is the Identity of the Muslim College Students in Germany?

RQ2: What is the relation between the Muslim College Students in Germany and the Society?

RQ3: What is the relation between the Muslim College Students in Germany and the Media?

Answering the question of whether the Muslim college students interviewed were having the German or a nonGerman identity, 9 of 10 students answered that they do not have a German identity and that they are keeping their hometown identity instead. They refuse to give up 
on their identity and blend in German society. The only exception to this was a Muslim German convert who is originally German. This shows that most of the student has a feeling of being the other in German society and can never feel fully integrated into German society.

This leads to the second question where students were asked to describe the relationship between them and society, whether they are involved in political or societal activities. Most of the college students did not participate in any of these activities but would prefer to participate in Muslim activities on a political or societal level. Again, this is an indication of the "Otherness" described in the literature.

The third research question would ask the college students to describe their media usage whether the traditional or the new media. 6 of 10 of the interviewed students were only using social media that is mainly concerned with their ethnic or religious community. Because of the language barrier and the lack of time and willingness, only 2 students followed German TV channels and or newspapers and magazines. This is another indication for the lack of involvement of the Muslim students in the German life and the feeling that they are the other.

\section{Limitations:}

One of the challenges I have faced was the unwillingness of some of the Muslim college students to be interviewed because they felt as members of marginalized groups. I have chosen the university campus (the cafeteria, the garden, the library or in front of the mosque) to conduct the interviews.

Due to the small sample of this paper, the results of 
this paper cannot be generalized and only represent the two universities that I have chosen from Germany. There is also a gender imbalance in this study as males were more willing to answer the interview and come and join me.

\section{Recommendations:}

One possible recommendation would be investigating more college students in other German universities and compare some other students from different parts of Germany together. Another possible research idea would be to compare the attitudes of college students in Germany with school students and see whether the age group affects the awareness of youth towards otherness. One could also conduct a comparative study between college students in several western European countries and measure how different the feeling of otherness differs or not. A survey could also be conducted to reach a greater number of students and result in quantitative results. 


\section{References:}

-Al-Saidi, H., \& Ahmed, A. (2014). Post-colonialism Literature the Concept of self and the other in Coetzee's Waiting forthe Barbarians: An Analytical Approach. Journal of Language Teaching \& Research, 5(1), 95-105. doi: $10.4304 /$ jltr.5.1.95-105

-Anderson, B. (1983). Imagined communities: Reflections on the origin and spread of nationalism. London, England: Verso.

-Brons, L. L. (2015). Othering, an Analysis. Transcience, a Journal of Global Studies, 6(1), 69-90. ISSN 21911150

-Boyce, C., \& Neale, P. (2006). Conducting in-depth interviews: A guide for designing and conducting in-depth interviews for evaluation input. Pathfinder International Tool Series, Monitoring and Evaluation - 2. Retrieved from

http://www2.pathfinder.org/site/DocServer/m_e_tool_ series_indepth_interviews.pdf.

-Cahoone, L. (2003). Introduction. In L. Cahoone (Ed.), From Modernism to Postmodernism: An Anthology (2nd Ed., pp. 1-13). Malden, MA: Blackwell Publishing.

-Crang, M. (1998). Cultural Geography: Routledge Contemporary Human Geography. New York. NY: Routledge. Retrieved from

h t t p s : / / b o o k s.goog l e.com.eg / books? $i d=1$ VCAAAAAQBAJ\&source=gbs_navlinks_s OPEN UNIVERSITY PRESS

Buckingham · Philadelphia

-Cottle, S. (2000). Ethnic minorities and the media: changing cultural boundaries. Buckingham, Philadelphia: Open University Press. Retrieved from https://www. researchgate.net/publication/268518927_Ethnic_ Minorities_and_the_Media_Changing_Cultural_ 
Boundaries

-De Beauvoir, S. (1949) Le Deuxieme Sexe, Paris, France: Gallimard. Retrieved from https://cdn.frenchpdf. com/wp/2019/01/07083802/Le-deuxieme-sexe-tome2-Simone-de-Beauvoir-FRENCHPDF.COM_.pdf

-Gutman, E. (2018). Germany as a" Melting Pot"? Conceptions of Otherness Over Time (Doctoral dissertation, Brandeis University). Retrieved from http://bir.brandeis.edu/bitstream/handle/1019235779// GutmanThesis2018. pdf? sequence $=3$ \&isAllowed $=y$ -Lenette, C. (2018). Visual Depictions of Refugee Camps:(De) Constructing Notions of Refugee-ness. In P. Liamputtong (ed.) Handbook of Research Methods in Health Social (pp. 1-19). Singapore: Springer.

-Malika, J., Ruepke, J. \& Wobbe, T. (2007). Religion und Medien: Vom Kultbild Zum Interritual. Münster, Germany: Aschendorff.

-Pirner, M., \& Lahnemann, J. (Eds) (2013) Media Power and Religions: The Challenge facing intercultural dialogue and learning (pp.42). Bern, Switzerland: Peter Lang, Internationaler Verlag der Wissenschaften.

-Said, E. (1978). Orienatlism. New Delhi, India: Penguin Books India.

-Staszak, J. F. (2009). Other/Otherness. In: Kitchin \& Thrift (Ed.). International Encyclopedia of Human Geography: A 12-Volume Set (pp. 43-47). Oxford, UK: Elsevier Science.

-Strumska-Cylwik, L. (2013). 'Other'/'Otherness' in a Multicultural World and their Diverse Qualities and Varieties in the Context of an Applied 'logic of Reverse'. International Journal of Arts \& Sciences, 6(1), 35-55.

-Vaquero, I. U. (Ed.). (2011). Media, migration and public 
opinion: Myths, prejudices and the challenge of attaining mutual understanding between Europe and North Africa. Bern, Switzerland: Peter Lang, Internationaler Verlag der Wissenschaften.

- Van Dijk, T. A. (2000). New (s) racism: A discourse analytical approach. Ethnic minorities and the media, 37, 33-49. Retrieved from

http://www.discourses.org/OldArticles/New(s)\%20 racism $\% 20 \% 20 \mathrm{~A} \% 20$ discourse $\% 20$ analytical\% 20 approach.pdf

\section{Appendix}

Interview guide for the In-depth interviews

Subheading One: Identity

1.1 Demographics:

1.1.1. Age:

1.1.2. City:

1.1.3. Gender:

1.1.4. Hijab:

1.1.5. Beard:

1.2. Education:

1.3. Muslim:

1.3.1. Sunni

1.3.2. Shiite

1.3.3. Secular

1.4. Ethnicity:

1.4.1. Egyptian

1.4.2. Pakistani

1.4.3. Syrian

1.4.4. German

1.4.5. Libyan 
1.4.6. other

1.5. Place of birth:

1.5.1. Inside Germany,

1.5.2. Outside Germany

1.6. Generation in Germany

1.7. Mother Language:

1.8. German language proficiency: Excellent- GoodLimited-None

1.9. Reason for living and Germany

1.10. Do you consider yourself as the other in German society generally and in the colleges specifically? How would you y describe your national identity or yourself? (German, Arab, Sunni, etc.)

1.11. What are the most important belongings of yours? (Family, ethnic group, college, social class, nationality)

2. Subheading Two: Relation with Society

2.1. Integration, Discrimination, Prejudices

2.1.1. Do you feel integrated into German society? (freedom of religion, freedom of religious practices, treatment with respect, equality, etc., compatibility between Islam and society)

2.1.2. Did you ever suffer from discrimination? Macro (legal and societal level) or micro-level (level of everyday life)

2.1.3. Do you think Germans look to you differently because of religion or it is because of your ethnicity, race, gender, skin color, language, accent, age, etc.

2.1.4. Do you feel integrated into German society, law, and everyday life?

2.2. Political and Community Engagement

2.2.1. Do you try to be part of Muslim organizations and/or mosques to feel integrated?

2.2.2. Do you try to integrate yourself through political 
and societal non-Muslim mainstream activities?

3. Subheading Three: Media

3.1. Mainstream Media

3.1.1. What is the relation between you and the mainstream media (television, newspapers, and websites) Are media presenting content in favor of various religious group?

3.1.2. What is your usage of SNS? (Facebook, Twitter, Instagram, Other)

3.1.3. Do you think that mainstream media is playing a role in the portrayal of Islam? (Positive, negative)

3.2. Minority Media (Diverse, Migrant media)

3.2.1. What is the relation between you and the diverse media (Websites etc.)?

3.2.2. Why do you or do you not use this media?

3.2.3. Do you think that the diverse media is playing a role in the portrayal of Islam? (Positive, negative) 
